\title{
The assessment of soil contamination with heavy metals in the Vladimir city
}

\author{
Ivan Kurochkin, Natalia Chugay, Ekaterina Kulagina* \\ Vladimir State University named after Alexander Grigoryevich and Nikolay Grigoryevich Stoletov, \\ 600000 Vladimir, Russia
}

\begin{abstract}
To analyze heavy metal contamination of urbanized soil in the Vladimir city, the soil was sampled and studied. The city area is represented by sod-medium podzolic and gray forest urbanized soil. Soil samples analysis included lead, zinc, copper, nickel, manganese, cobalt and chromium. The resulted parameters were compared to the maximum permissible concentrations and background values. The regularities between the studied sites proximity to the industrial enterprises and heavy metals concentration in soil have been found. The coefficients of heavy metals accumulation in soil have been calculated and the metals as priority pollutants with the highest accumulation coefficient have been identified. By calculating the cumulative accumulation index, the city area has been differentiated according to the hazardous degree. The research peculiarity comprises the sampling locations selection - school sites, as the child population is the most vulnerable to the diseases, associated with the heavy metals accumulation in soil.
\end{abstract}

\section{Introduction}

The industrialization and urbanization process causes the increase in the anthropogenic pollution level of the natural objects - atmosphere, soil and surface water, thus negatively affecting the living organism vital activity, including humans.

Soil is one of the key ecosystem elements, which is known to be formed as a result of the long-term exposure to biotic, abiotic and anthropogenic factors. Being a multi-level ecosystem, the crucial role in the heavy metal cycle belongs to soil. The heavy metals behavior in soil is still poorly studied, due to the huge variety of soils differing in composition, redox conditions, reactionary ability and complex biogeocenoses. Mercury, cadmium, lead and arsenic are the most toxic heavy metals - body poisoning caused by them might have serious consequences [1]. Such heavy metals as zinc, copper, and cobalt are less toxic and inhibit microbiological activity and reduce biological efficiency $[2,3]$.

Special attention is to be paid to the urban areas soil condition, as it performs important ecological functions, closes the substances biogeochemical cycles, regulates gas exchange, etc. $[4,5]$.

Nowadays anthropogenic activity contributes to the soil chemical contamination with heavy metals, which amount might exceed the actual standards. Gas and dust emission from

* Corresponding author: kylaginaek@mail.ru 
industrial enterprises and thermal power plants, as well as vehicle exhaust gases present the greatest danger for soil contamination with heavy metals.

The risk of soil contamination with heavy metals in concentration exceeding the maximum permissible limits is determined by the possibility of secondary air pollution with soil dust. As a result of heavy metal salts impact, the vital activity of soil microflora and microfauna is suppressed, soil biochemical processes are disrupted, causing vegetation deterioration or even death in this area [6-8].

The research objective is to assess heavy metal contamination of soils of the Vladimir city in order to identify the excess permissible concentrations, to analyze the spatial distribution of the contamination level and the influence rate of the major industrial enterprises on soil contamination with heavy metals.

\section{Materials and methods}

The research object is soil of the school areas, located within the city of Vladimir. The city itself is situated in the zone of sod-medium podzolic and gray forest soils [9]. However, the studies have been conducted in the urbanized areas, which are characterized by the blurred soil horizons, foreign inclusions, presented by construction debris, etc.

In this study, the points are key, and represent conditions of different distances from polluting enterprises, major highways, etc. In addition, we have interpolated the obtained values for the entire territory of the city, so the number of points is acceptable for assessing the pollution of a small city area.

The city of Vladimir is an industrial center of the district and an administrative center of the Vladimir region. In compliance with the available data $[10,11]$, the air basin of Vladimir is annually subjected to high load due to the gas and dust emissions from the city industrial enterprises and vehicles. Soil is polluted mainly due to gas and dust emissions from the following enterprises: "Plant Avtopribor 1td.", "Vladimir Chemical Plant PLC", "NPO Magneton PLC ", "VPO Tochmash PLC", "Vladimir Plant" Electropribor PLC " (Fig. 1).

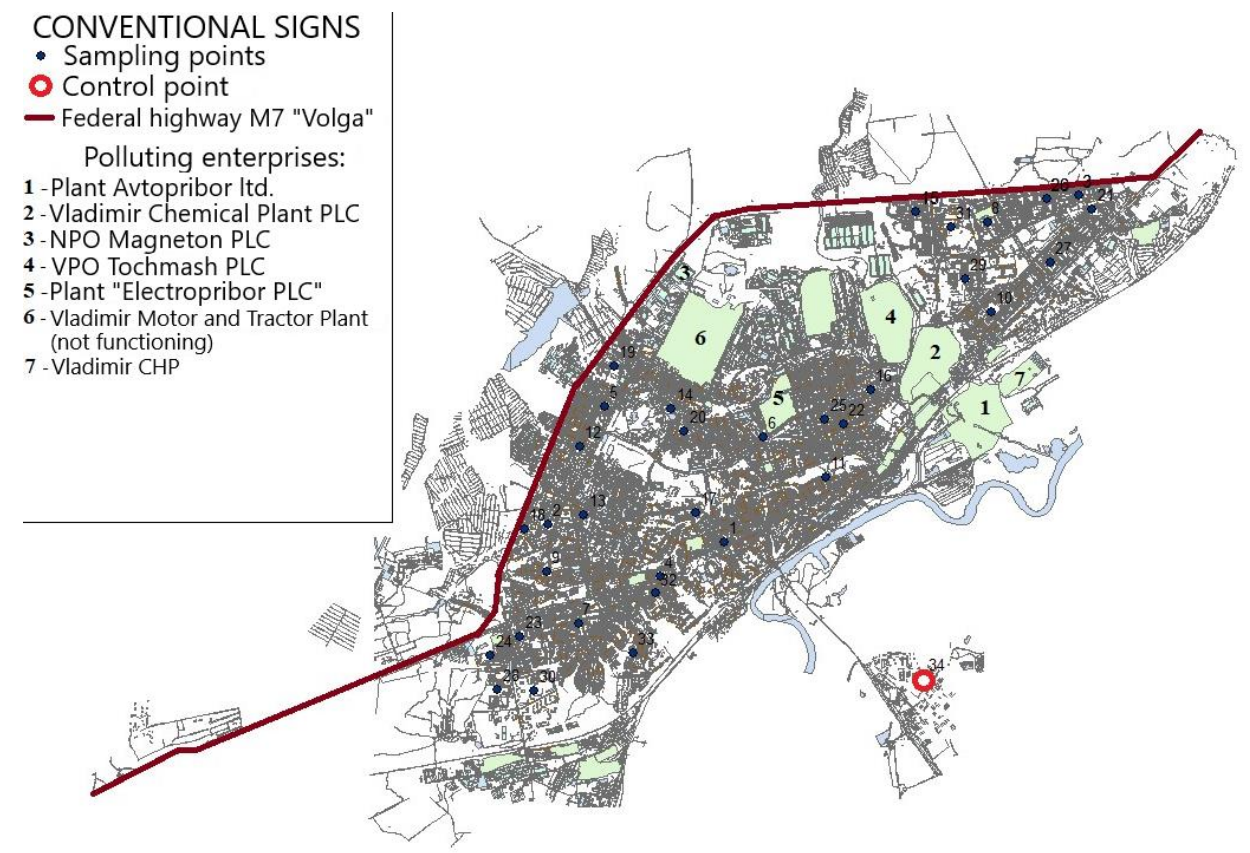

Figure 1. Sampling points 
The heavy metal contamination of the urbanized soils was assessed in three stages.

At the first stage, soil sampling and sample preparation were carried out in compliance with GOST 14.4.4.02-84 "Nature protection. Methods of sampling and samples preparation for chemical, microbiological and helminthological analysis" requirements. Samples were taken from the upper soil horizon at 34 points, located primarily in the residential city areas (Figure 1). One of the sampling points was located away from the main pollution sources, but nevertheless in the area within the city borders. It allows comparing the average pollution indicators in the city with the conditionally uncontaminated area.

At the second stage, the analysis of heavy metals content in the selected samples was carried out. The heavy metals concentration in the studied soil samples was determined by $\mathrm{X}$-ray fluorescence spectroscopy.

The third stage was devoted to the import of the received values into the raster model of the spatial data, and interpolation applying the tools of the ArcGIS geoinformation system for detecting heavy metal contamination in the Vladimir area.

\section{Results and discussion}

During the research, the amount of the basic heavy metals, producing the greatest impact on human health, was determined (Table 1).

Table 1. The content of heavy metals in the studied soil samples

\begin{tabular}{|l|l|l|l|l|l|l|l|}
\hline \multirow{2}{*}{$\begin{array}{l}\text { Sampling } \\
\text { point }\end{array}$} & \multicolumn{7}{|c|}{ Content of heavy metals, $\mathrm{mg} / \mathrm{kg}$} \\
\cline { 2 - 8 } & $\mathrm{Pb}$ & $\mathrm{Zn}$ & $\mathrm{Cu}$ & $\mathrm{Ni}$ & $\mathrm{Co}$ & $\mathrm{Mn}$ & $\mathrm{Cr}$ \\
\hline 1 & 99.3 & 415.5 & 49.0 & 18.5 & 1.2 & 314.7 & 54.8 \\
\hline 2 & 37.9 & 112.9 & 69.1 & 46.0 & 14.7 & 707.8 & 87.2 \\
\hline 3 & 190.2 & 125.5 & 64.5 & 39.6 & 15.2 & 774.2 & 86.9 \\
\hline 4 & 102.9 & 239.0 & 58.4 & 32.5 & 10.2 & 480.5 & 69.9 \\
\hline 5 & 60.9 & 141.6 & 48.6 & 30.2 & 3.4 & 427.0 & 62.8 \\
\hline 6 & 68.1 & 112.6 & 70.6 & 35.3 & 9.9 & 494.5 & 60.6 \\
\hline 7 & 99.6 & 118.5 & 64.0 & 29.8 & 7.7 & 386.7 & 64.1 \\
\hline 8 & 32.3 & 69.9 & 47.0 & 29.3 & 14.8 & 475.1 & 77.9 \\
\hline 9 & 192.7 & 365.0 & 74.3 & 35.6 & 8.9 & 307.7 & 70.8 \\
\hline 10 & 103.7 & 193.7 & 46.2 & 40.0 & 15.2 & 437.9 & 75.7 \\
\hline 11 & 68.9 & 209.4 & 63.0 & 44.3 & 6.0 & 332.5 & 69.1 \\
\hline 12 & 51.5 & 137.7 & 42.0 & 26.3 & 8.2 & 412.3 & 60.3 \\
\hline 13 & 77.4 & 145.6 & 48.0 & 33.2 & 6.5 & 472.8 & 69.4 \\
\hline 14 & 43.3 & 10.7 & 36.6 & 5.7 & 4.5 & 235.6 & 40.8 \\
\hline 15 & 43.4 & 86.1 & 46.4 & 30.4 & 4.7 & 380.5 & 66.4 \\
\hline 16 & 82.2 & 455.7 & 56.4 & 33.9 & 7.3 & 432.5 & 73.7 \\
\hline 17 & 75.8 & 159.7 & 48.3 & 23.8 & 6.5 & 351.9 & 55.8 \\
\hline 18 & 90.0 & 132.6 & 45.8 & 30.0 & 5.6 & 528.6 & 67.3 \\
\hline 19 & 61.3 & 61.0 & 58.1 & 25.3 & 8.6 & 268.9 & 58.7 \\
\hline 20 & 79.7 & 282.6 & 56.9 & 40.7 & 6.5 & 526.6 & 84.3 \\
\hline 21 & 55.6 & 103.4 & 57.6 & 39.8 & 16.0 & 720.6 & 88.1 \\
\hline 22 & 103.4 & 852.8 & 62.4 & 31.1 & 8.4 & 485.9 & 80.9 \\
\hline 23 & 90.0 & 132.6 & 45.8 & 30.0 & 5.6 & 527.8 & 67.3 \\
\hline 24 & 77.1 & 161.1 & 42.9 & 22.8 & 6.3 & 292.2 & 55.6 \\
\hline 25 & 80.2 & 151.8 & 50.4 & 24.4 & 6.1 & 386.0 & 51.8 \\
\hline
\end{tabular}




\begin{tabular}{|l|l|l|l|l|l|l|l|}
\hline 26 & $\mathbf{5 5 . 2}$ & $\mathbf{2 2 0 . 4}$ & $\mathbf{7 4 . 3}$ & $\mathbf{3 9 . 9}$ & $\mathbf{9 . 7}$ & $\mathbf{5 4 8 . 7}$ & $\mathbf{8 8 . 1}$ \\
\hline 27 & 39.5 & 100.6 & 54.3 & 29.8 & 10.9 & 503.8 & 67.8 \\
\hline 28 & 56.2 & 63.6 & 54.2 & 24.4 & 8.0 & 434.7 & 64.9 \\
\hline 29 & 36.3 & 95.7 & 71.4 & 40.9 & 11.0 & 719.8 & 81.0 \\
\hline 30 & 46.6 & 93.5 & 56.3 & 31.6 & 8.7 & 309.2 & 58.2 \\
\hline 31 & 67.8 & 58.9 & 56.7 & 24.2 & 7.5 & 287.5 & 64.5 \\
\hline 32 & 44.6 & 127.1 & 51.5 & 29.5 & 5.5 & 473.5 & 71.7 \\
\hline 33 & 66.1 & 65.4 & 55.5 & 26.0 & 8.4 & 327.1 & 75.1 \\
\hline $\begin{array}{l}34 \\
\text { (control) }\end{array}$ & 56.4 & 39.0 & 30.5 & 11.3 & 3.6 & 175.9 & 46.1 \\
\hline $\begin{array}{l}\text { Average } \\
\text { values }\end{array}$ & 74.6 & 171.8 & 54.6 & 30.5 & 8.3 & 439.4 & 68.2 \\
\hline
\end{tabular}

The backgrounds areas for heavy metals in soils of Vladimir are: $\mathrm{Pb}-16 \mathrm{mg} / \mathrm{kg}, \mathrm{Zn}-48$ $\mathrm{mg} / \mathrm{kg}, \mathrm{Cu}-48 \mathrm{mg} / \mathrm{kg}, \mathrm{Ni}-60 \mathrm{mg} / \mathrm{kg}, \mathrm{Co}-12 \mathrm{mg} / \mathrm{kg}, \mathrm{Mn}-1050 \mathrm{mg} / \mathrm{kg}, \mathrm{Cr}-70 \mathrm{mg} / \mathrm{kg}$ [11].

Comparing the received results with the actual sanitary standards [13], it was revealed that the average content of heavy metals in soil samples from various districts of Vladimir exceeds the average content of heavy metals in control soil samples. It might depend on the industrial emissions from the enterprises, located within the city area of Vladimir and a large number of motor vehicles. In the western and central city parts $\mathrm{Zn}, \mathrm{Cu}$, and $\mathrm{Pb}$ are the priority pollutants. The received indicators of zinc amount in soil exceed the background value by 2.3 times. The background values excess for lead concentration is 4.7 times, copper -2 times. In the western districts of the city, the priority pollutants are exhaust gases of the traffic flows, passing along the main city highways.

The excessive heavy metals content in the soil of the central and eastern parts of the city can be associated with the large number of industrial zones located in this area. These are the Vladimir Chemical Plant, Avtopribor and Electropribor plants, the Vladimir thermal power plant, and the adjacent industrial area. Besides, contamination depends on considerable traffic, as this area is located at the confluence of two major highways: the federal highway M7 "Volga" and one of the central highways of the Vladimir city (Suzdal Avenue).

To identify the level of heavy metal contamination of the soils in Vladimir city, the results have been plotted on the raster city map, and then, applying the tools of ArcGIS geographic information system, interpolated surfaces have been created reflecting the concentration between the analyzed points.

Thus, cobalt concentration in urban soils exceeds the maximum permissible concentration almost throughout the city area, but for the small area in the central part of the city, as well as the area separated from the main industrial zones by the river. The highest cobalt concentration has been detected in the north-western part of the city, depending on the proximity to the federal highway M7, as well as everywhere in the eastern part of the city, where the wind might blow most of the pollutants released into the atmosphere by large enterprises of the city - the Vladimir Chemical Plant, "VPO Tochmash" and the city thermal power plant.

Copper concentration (Figure 2) exceeds the background values almost everywhere in the city. Judging by this element content, the city area is significantly contaminated. 


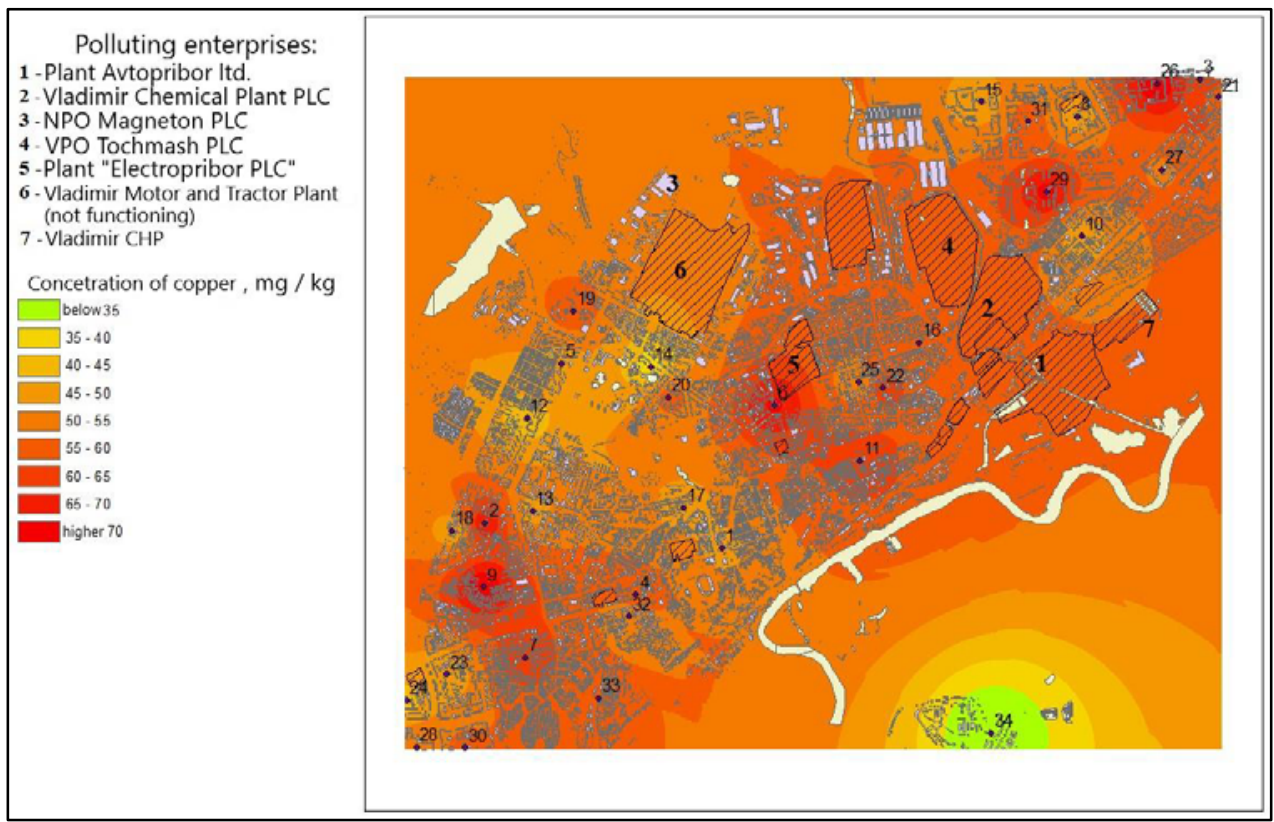

Figure 2. Indicators of copper concentration in urban soils

The soil contamination with lead ranks the most intense situation (Figure 3 ). The excess of the background values and maximum permissible concentrations is revealed almost everywhere, in some areas the maximum permissible concentration is 4 times higher or more. The high concentration of lead in urban soil also depends on industrial enterprises, including chemical industry, as well as vehicles traffic passing through the city. Foci of the low lead concentration, not exceeding MPC and background values, are detected in residential areas in the eastern part of the city.

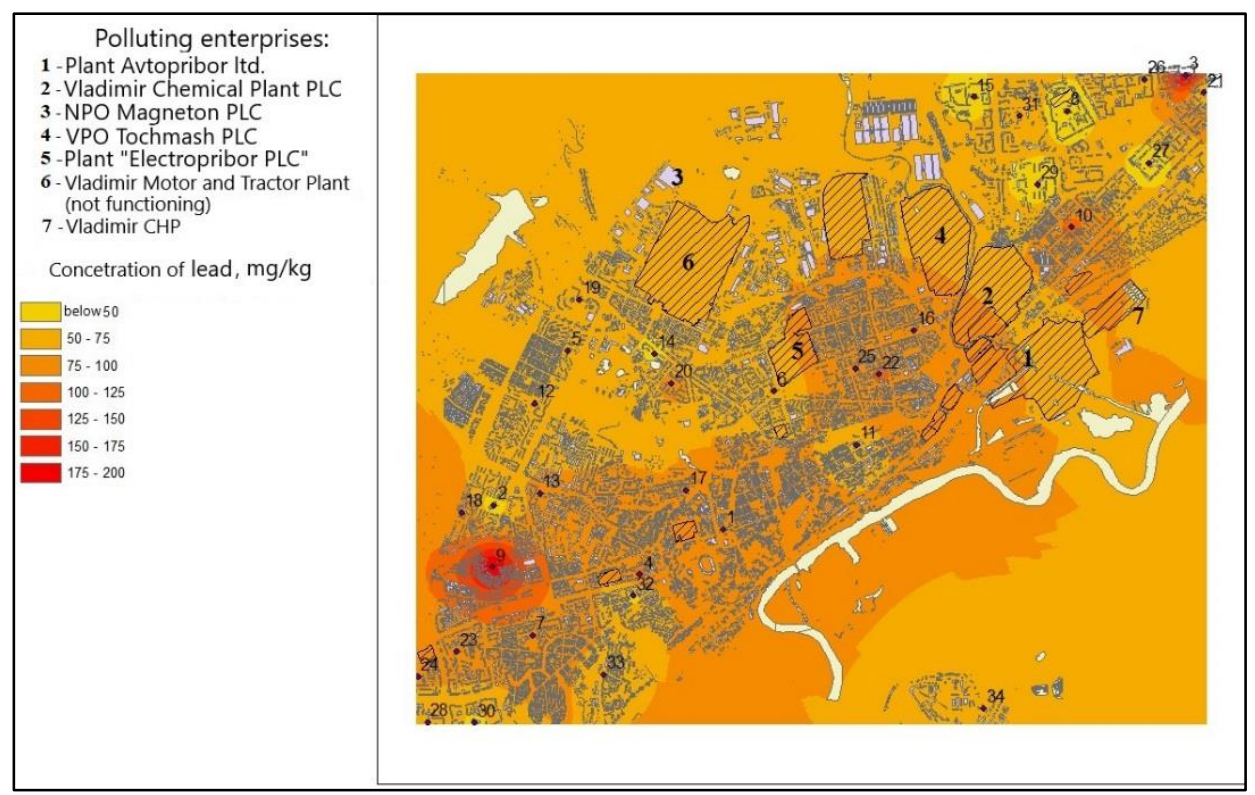

Figure 3. Indicators of lead concentration in urban soils 
The maximum permissible concentration of chromium $(100 \mathrm{mg} / \mathrm{kg})$ in the city is not exceeded, but in some areas the contamination degree is up to 0.9 MPC. These areas are basically situated in the eastern part.

The distribution of manganese and nickel concentrations is similar to that of cobalt and generally tends to the increased concentrations in the eastern direction, where it depends on the pollutants emission into the atmosphere by industrial enterprises. No MPC excess for manganese and nickel concentration in the soils was detected; the background values were slightly exceeded only in some areas.

The highest zinc concentration (Figure 4) is observed in the areas near the major industrial enterprises. In contrast to other heavy metals, the reverse trend is observed towards the soil contamination decrease in the eastern direction. However, MPC is exceeded in large areas. The areas situated rather far from the major enterprises - polluters are naturally characterized by low concentration.

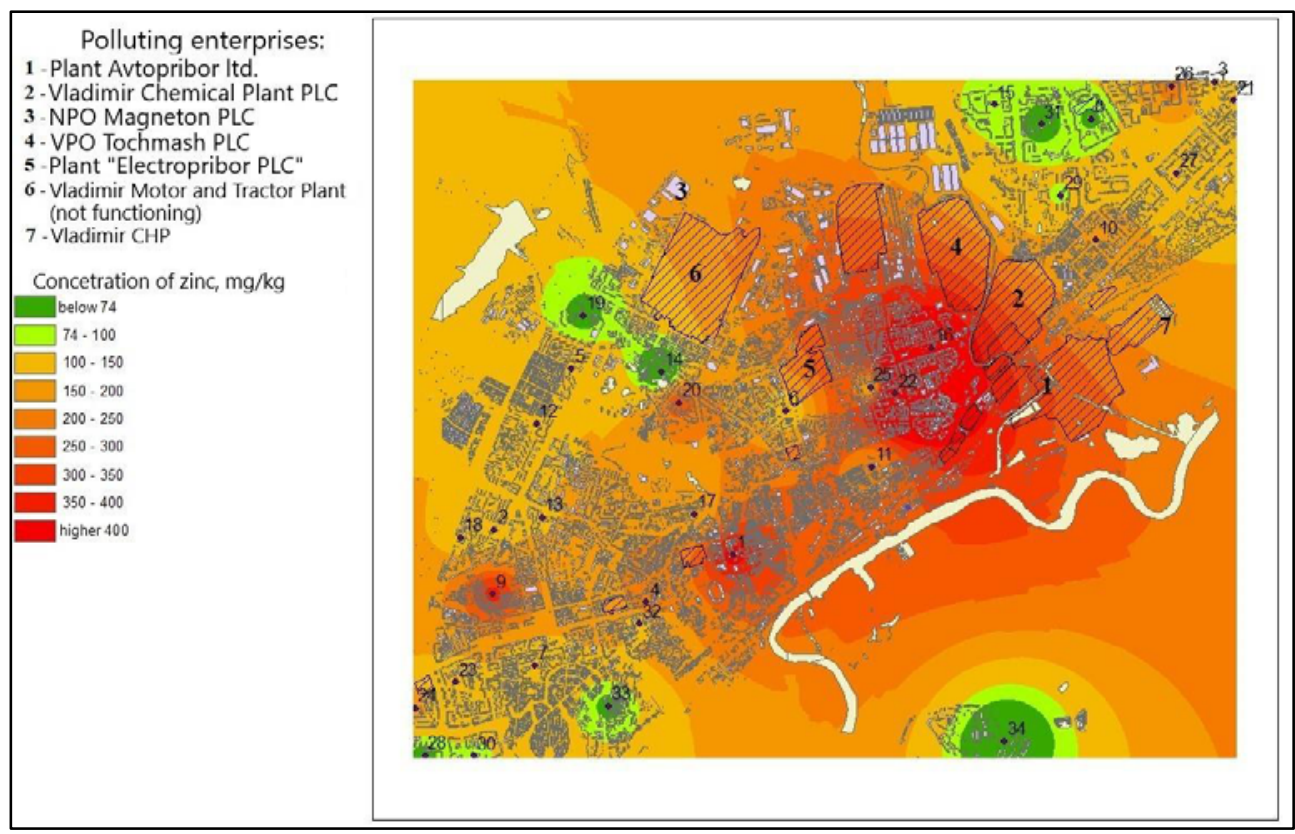

Figure 4. Indicators of zinc concentration in urban soils

To determine the soil contamination degree with heavy metals, the coefficient of heavy metals accumulation in soil has been calculated:

$$
\mathrm{K}_{\mathrm{a}}=\frac{\mathrm{C}_{\mathrm{i}}}{\mathrm{C}_{\mathrm{bi}}}
$$

where: $K_{a}$ - accumulation coefficient; $C_{i}$ - heavy metals content in soil $(\mathrm{mg} / \mathrm{kg}) ; \mathrm{C}_{\mathrm{bi}}-$ background heavy metals content in soil $(\mathrm{mg} / \mathrm{kg})$.

The calculating results of the accumulation coefficient are presented in Table 2.

Table 2. Coefficients of accumulation of heavy metals by soils

\begin{tabular}{|l|l|l|l|l|l|l|l|}
\hline $\begin{array}{l}\text { Sampling } \\
\text { point }\end{array}$ & $\mathrm{Pb}$ & $\mathrm{Zn}$ & $\mathrm{Cu}$ & $\mathrm{Ni}$ & $\mathrm{Co}$ & $\mathrm{Mn}$ & $\mathrm{Cr}$ \\
\hline 1 & 6.21 & 5.62 & 1.40 & 0.44 & 0.12 & 0.63 & 1.10 \\
\hline 2 & 2.37 & 1.53 & 1.97 & 1.09 & 1.47 & 1.42 & 1.74 \\
\hline 3 & 11.89 & 1.70 & 1.84 & 0.94 & 1.52 & 1.55 & 1.74 \\
\hline
\end{tabular}




\begin{tabular}{|c|c|c|c|c|c|c|c|}
\hline 4 & 6.43 & 3.23 & 1.67 & 0.77 & 1.02 & 0.96 & 1.40 \\
\hline 5 & 3.81 & 1.91 & 1.39 & 0.72 & 0.34 & 0.85 & 1.26 \\
\hline 6 & 4.26 & 1.52 & 2.02 & 0.84 & 0.99 & 0.99 & 1.21 \\
\hline 7 & 6.23 & 1.60 & 1.83 & 0.71 & 0.77 & 0.77 & 1.28 \\
\hline 8 & 2.02 & 0.94 & 1.34 & 0.70 & 1.48 & 0.95 & 1.56 \\
\hline 9 & 12.04 & 4.93 & 2.12 & 0.85 & 0.89 & 0.62 & 1.42 \\
\hline 10 & 6.48 & 2.62 & 1.32 & 0.95 & 1.52 & 0.88 & 1.51 \\
\hline 11 & 4.31 & 2.83 & 1.80 & 1.05 & 0.60 & 0.67 & 1.38 \\
\hline 12 & 3.22 & 1.86 & 1.20 & 0.63 & 0.82 & 0.82 & 1.21 \\
\hline 13 & 4.84 & 1.97 & 1.37 & 0.79 & 0.65 & 0.95 & 1.39 \\
\hline 14 & 2.71 & 0.14 & 1.04 & 0.14 & 0.45 & 0.47 & 0.82 \\
\hline 15 & 2.71 & 1.16 & 1.33 & 0.72 & 0.47 & 0.76 & 1.33 \\
\hline 16 & 5.14 & 6.16 & 1.61 & 0.81 & 0.73 & 0.86 & 1.47 \\
\hline 17 & 4.74 & 2.16 & 1.38 & 0.57 & 0.65 & 0.70 & 1.12 \\
\hline 18 & 5.63 & 1.79 & 1.31 & 0.71 & 0.56 & 1.06 & 1.35 \\
\hline 19 & 3.83 & 0.82 & 1.66 & 0.60 & 0.86 & 0.54 & 1.17 \\
\hline 20 & 4.98 & 3.82 & 1.63 & 0.97 & 0.65 & 1.05 & 1.69 \\
\hline 21 & 3.48 & 1.40 & 1.65 & 0.95 & 1.60 & 1.44 & 1.76 \\
\hline 22 & 6.46 & 11.52 & 1.78 & 0.74 & 0.84 & 0.97 & 1.62 \\
\hline 23 & 5.63 & 1.79 & 1.31 & 0.71 & 0.56 & 1.06 & 1.35 \\
\hline 24 & 4.82 & 2.18 & 1.23 & 0.54 & 0.63 & 0.58 & 1.11 \\
\hline 25 & 5.01 & 2.05 & 1.44 & 0.58 & 0.61 & 0.77 & 1.04 \\
\hline 26 & 3.45 & 2.98 & 2.12 & 0.95 & 0.97 & 1.10 & 1.76 \\
\hline 27 & 2.47 & 1.36 & 1.55 & 0.70 & 1.09 & 1.01 & 1.36 \\
\hline 28 & 3.51 & 0.86 & 1.55 & 0.58 & 0.80 & 0.87 & 1.30 \\
\hline 29 & 2.27 & 1.29 & 2.04 & 0.97 & 1.10 & 1.44 & 1.62 \\
\hline 30 & 2.91 & 1.26 & 1.61 & 0.75 & 0.87 & 0.62 & 1.16 \\
\hline 31 & 4.24 & 0.80 & 1.62 & 0.58 & 0.75 & 0.58 & 1.29 \\
\hline 32 & 2.79 & 1.72 & 1.47 & 0.70 & 0.55 & 0.95 & 1.43 \\
\hline 33 & 4.13 & 0.88 & 1.59 & 0.62 & 0.84 & 0.65 & 1.50 \\
\hline 34 & 3.53 & 0.53 & 0.88 & 0.27 & 0.36 & 0.35 & 0.92 \\
\hline
\end{tabular}

The resulted data reveals that the priority soil pollutants are: $\mathrm{Pb}$ - accumulation coefficient $-2,02-12,04 ; \mathrm{Zn}-0,14-11,52$ and $\mathrm{Cu}-0,87-2,12$.

To determine the soil contamination level with heavy metals, as well as to assess the environmental situation, the cumulative indicator of contamination $\left(Z_{c}\right)$ with these elements is calculated, which allows sanitarily feasible differentiating of the area according to the hazardous rate. The soil contamination cumulative indicator with the elements was calculated according to the formula $[14,15]$ :

$$
\mathrm{Z}_{\mathrm{c}}=\sum_{1}^{\mathrm{n}} \mathrm{K}_{i}-(\mathrm{n}-1)
$$

where: $\mathrm{Zc}$ is cumulative indicator of soil contamination with heavy metals;

$\mathrm{K}_{\mathrm{i}}$ - concentration coefficient of the $\mathrm{i}$-th pollution component;

$\mathrm{n}$ - the number of summable substances to be determined.

The environmental assessment of soil pollution according to the cumulative indicator of $Z_{c}$ pollution was carried out using officially approved standards [16]. The calculation results of the cumulative pollution indicator are presented in Table 3. 
Table 3. Values of the total indicator of soil pollution

\begin{tabular}{|c|c|c|}
\hline Sampling point & $Z_{c}$ & Pollution level \\
\hline 1 & 9,51 & Acceptable \\
\hline 2 & 5,59 & Acceptable \\
\hline 3 & 16,18 & Moderately dangerous \\
\hline 4 & 9,48 & Acceptable \\
\hline 5 & 4,28 & Acceptable \\
\hline 6 & 5,82 & Acceptable \\
\hline 7 & 7,19 & Acceptable \\
\hline 8 & 2,99 & Acceptable \\
\hline 9 & 16,87 & Moderately dangerous \\
\hline 10 & 9,28 & Acceptable \\
\hline 11 & 6,64 & Acceptable \\
\hline 12 & 3,76 & Acceptable \\
\hline 13 & 5,95 & Acceptable \\
\hline 14 & 0 & Acceptable \\
\hline 15 & 2,48 & Acceptable \\
\hline 16 & 10,78 & Acceptable \\
\hline 17 & 5,31 & Acceptable \\
\hline 18 & 6,4 & Acceptable \\
\hline 19 & 3,49 & Acceptable \\
\hline 20 & 8,78 & Acceptable \\
\hline 21 & 6,27 & Acceptable \\
\hline 22 & 17,94 & Moderately dangerous \\
\hline 23 & 6,4 & Acceptable \\
\hline 24 & 5,09 & Acceptable \\
\hline 25 & 5,5 & Acceptable \\
\hline 26 & 7,33 & Acceptable \\
\hline 27 & 3,54 & Acceptable \\
\hline 28 & 3,47 & Acceptable \\
\hline 29 & 4,74 & Acceptable \\
\hline 30 & 3,19 & Acceptable \\
\hline 31 & 3,84 & Acceptable \\
\hline 32 & 3,61 & Acceptable \\
\hline 33 & 4,22 & Acceptable \\
\hline 34 & 0,83 & Acceptable \\
\hline
\end{tabular}

As for the concentration indicators of individual heavy metals, the values received in determining the cumulative indicator of soil pollution have been plotted on the city raster map. Afterwards with the help of ArcGIS geoinformation system, interpolated surfaces have been created, reflecting the cumulative pollution index between the sampling points (Figure $5)$. 


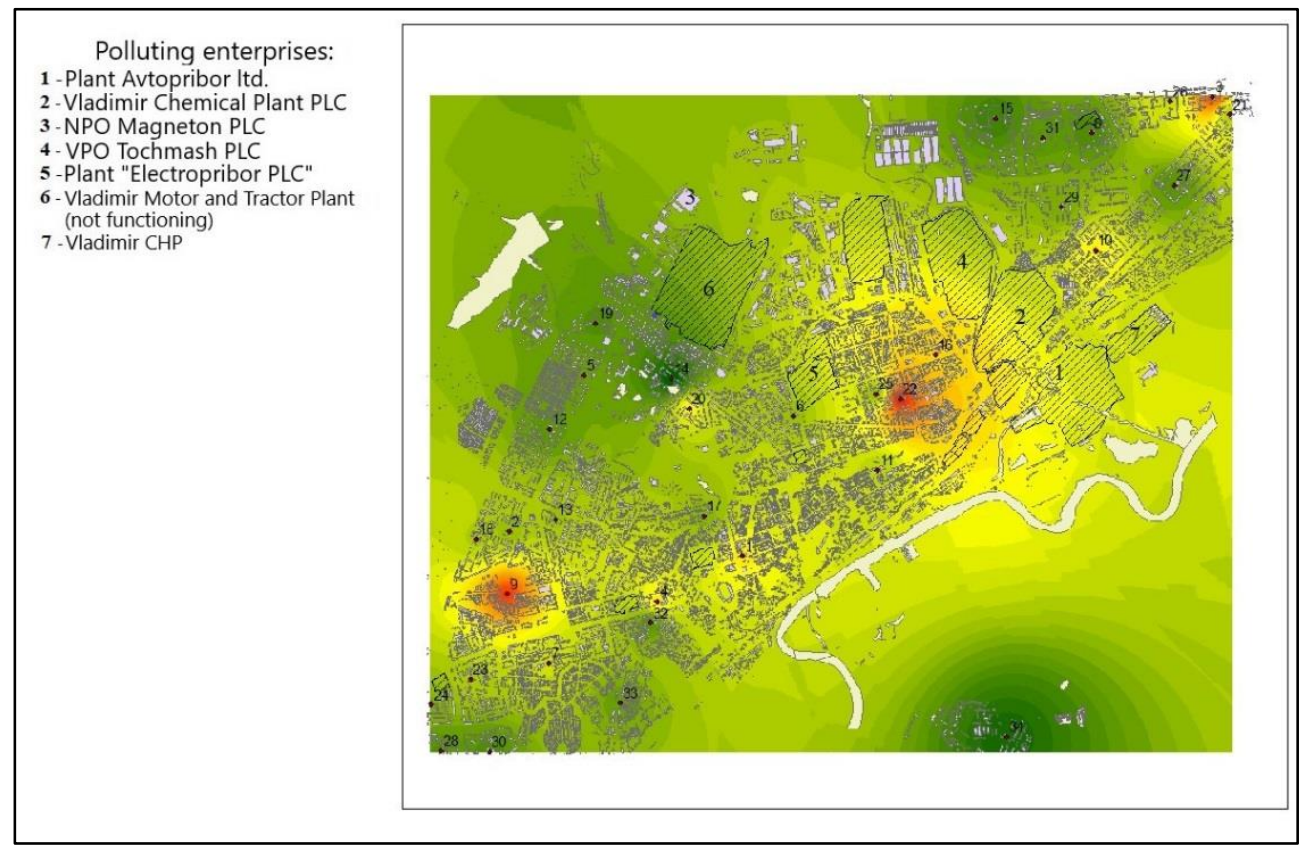

Figure 5. Cumulative pollution index of soil contamination with heavy metals

\section{Conclusion}

Having analyzed the indicators of heavy metal concentrations in the soil of Vladimir city, it was confirmed that the industrial enterprises proximity to the residential areas entails the pollutants accumulation in the soil, which, at high concentrations, might cause danger for human health. The most hazardous situation is soil contamination with lead, where more than 4 times excess has been recorded. Besides it has been revealed that the highest heavy metals concentrations are observed in residential areas of the eastern part of the city, in the immediate vicinity of the major enterprises-polluters. Lower concentrations in the western part of the city depend on the prevailing westerly wind direction in the city. Soil contamination with manganese and nickel is moderate - slight excess of background values has been detected. In the city area, where the control point is located, the minimum concentrations of heavy metals are recorded. Moreover low pollution level is observed in the south-western part of the city, which is practically not subject to the heavy metals accumulation due to the long distance from the enterprises-polluters.

The priority soil pollutants in the city of Vladimir are lead, copper and zinc, characterized by the highest accumulation coefficient. The pollution level of urban soils basing on the total pollution indicator as a whole can be described as "acceptable".

\section{References}

1. V. M. Boev, V.V. Bystrikh, A.V. Gorlov, A.I. Karpov, V.I. Kudrin Urbanized habitat and human health (Dimur, Orenburg, 2004)

2. J. Kharkan, M.H. Sayadi, M.R. Rezaei, Environmental health engineering and management journal, 1 (6), 17-25 (2019)

3. C.V. Evans, D.S. Fanning, J.R. Short, Agron. Monogr. 39, 33-67 2000) 
4. Yu.E. Saet, B.A. Revich, E.P. Yanin et al., Environmental Geochemistry (Nedra, Moscow, 1990)

5. R.S. Zokirov, O.A. Neverova, Bulletin of the Irkutsk State Agricultural Academy, 5(7), 44-50 (2011)

6. T.R. Shi, J. Ma, Y.Y. Zhang, C.S., Env. Int., 129, 35-41 (2019)

7. A.A. Oberemchenko, Bulletin of Science and Practice,44-7, 28-39 (2019)

8. S.S. Voronich, N.N. Roeva, N.N. Grebenkin et al., Ecology of urbanized territories, 1, 122-126 (2019)

9. Ecological atlas of the Klyazma River basin: Man in the environment (VISU Publ, Vladimir, 2018)

10. A.A. Martsev, Environmental factors impact on population morbidity of the Vladimir region: Thesis Abstract Cand.of Biology (V1SU, Vladimir, 2015)

11. T.A. Trifonova, N.V. Chugay, E.Yu. Kulagina, I.N. Kurochkin, A.N. Krasnoshchekov, M.V. Larionov, AgroEcoInfo, 1(39), 8 (2020).

12. On the state of environment and population health of the Vladimir region in 2016: annual report (Transit-X, Vladimir, 2017)

13. Hygienic standards HS 2.1.7.2041-06 "Maximum permissible concentrations (MPC) of chemicals in soil»

14. S.M. Chesnokova, Chemical methods of environmental objects analysis: laboratory practice (V1SU Publ. House, Vladimir, 1996)

15. I. N. Volkova, G. V. Kondakova, Ecological Soil Science: Laboratory classes for environmental students (Bachelors): Method. instructions (Yaroslavl State University, Yaroslavl, 2002)

16. Methodological guidelines MG 2.1.7.730-99 "Hygienic assessment of the soil quality in populated areas" 